\section{Inhalation trauma due to overheating in a microwave oven}

\author{
A L Zanen, A P Rietveld
}

\begin{abstract}
The microwave oven is a kitchen appliance that has become increasingly popular in recent years. In some instances the temperature in the microwave oven can become exceedingly high. A case is discussed of a patient with respiratory distress after inhalation of gas from an overheated microwave oven.
\end{abstract}

(Thorax 1993;48:300-302)

\section{Case report}

A 26 year old woman presented to the outpatient department of our hospital with acute dyspnoea. Shortly before she had been cooking potatoes in a microwave oven, using conventional microwave containers for that purpose. As a result of the development of smoke, she had opened the door of the microwave oven and removed the container with the cooked potatoes. A few minutes later her two pet parakeets that were in the kitchen dropped dead. Approximately half an hour later the woman began to experience feelings of dyspnoea and tightness around the chest, and developed a non-productive cough. The complaints became increasingly intense over the next few minutes.

There was a history of a left sided nephrectomy and irradiation for a Wilms' tumour at the age of two years. Otherwise she had always been healthy. There was no history of dyspnoea on exertion or at rest and no wheezing or cough. She did not take any medicine and did not smoke.

On physical examination her temperature was $37^{\circ} \mathrm{C}$, pulse rate $124 /$ minute and blood pressure $140 / 80$. The respiratory rate was $36 /$ minute. The patient appeared anxious and in respiratory distress. She had a dry cough, but no cyanosis was observed and there was no rash. The heart sounds were normal; no murmurs, friction rub or gallop sounds were heard. Examination of the lungs disclosed harsh vesicular breath sounds with very fine crepitations.

The erythrocyte sedimentation rate was $14 \mathrm{~mm}$ in the first hour. Haemoglobin was $12.0 \mathrm{mg} / 100 \mathrm{ml}$, and the white cell count was elevated to $41.7 \times 10^{9} / 1$. The differential count showed $1 \%$ metamyelocytes, $7 \%$ rod shaped white cells, $88 \%$ neutrophils, 3\% lymphocytes, and $1 \%$ monocytes. The platelet count was $319 \times 10^{9} / 1$. Results of renal function tests and electrolyte levels were within normal limits. A specimen of arterial blood, drawn while the patient was breathing air at room temper- ature, showed that the $\mathrm{pH}$ was $7 \cdot 41$, the carbon dioxide tension $\left(\mathrm{PCO}_{2}\right)$ was $34.5 \mathrm{~mm} \mathrm{Hg}$ $(4.6 \mathrm{kPa})$, the oxygen tension $\left(\mathrm{PO}_{2}\right)$ was $54.2 \mathrm{~mm} \mathrm{Hg}(7.2 \mathrm{kPa})$, and the oxygen saturation was $89 \%$. Serological tests for psittacosis gave negative results. The electrocardiogram was normal. Chest radiography disclosed a diffuse bilateral fine reticular pattern at the lung bases (fig 1). Pulmonary function tests, performed the day after admission, showed a restrictive ventilatory defect with decreased diffusion capacity (table). Oxygen ( $3 \mathrm{l} /$ minute) and prednisolone $(25 \mathrm{mg}$ intravenously) were administered. The following day the dyspnoea had diminished, and the blood gas tensions and chest radiograph were normal. Pulmonary function indices, however, were still abnormal.

The dead parakeets were retrieved for postmortem examination a few hours after the incident. Microscopic examination disclosed considerable hyperaemia of the lung parenchyma with almost total atelectasis. In the alveoli there was an accumulation of protein, debris, and blood cells. In the bronchi there was also much debris and evidence of multiple haemorrhages (fig 2). Bacteriological examination of the lungs gave negative results.

The microscopic appearance was consistent with toxic damage caused by inhalation of a poisonous gas. Inspection of the microwave oven disclosed that a small Teflon block, used as an axle for a rotating platform, was partially melted and the platform, made of glass, was cracked. The food container was not damaged.

One month after the incident the patient still had exertional dyspnoea and the pulmonary function values remained abnormal (table).

\section{Discussion}

The relationship in time between the inhalation of smoke from the overheated microwave oven, the development of dyspnoea in the patient, and the sudden death of the parakeets makes a causal relationship probable. Objective evidence included hypoxaemia on blood gas analysis, a diffuse pulmonary infil-

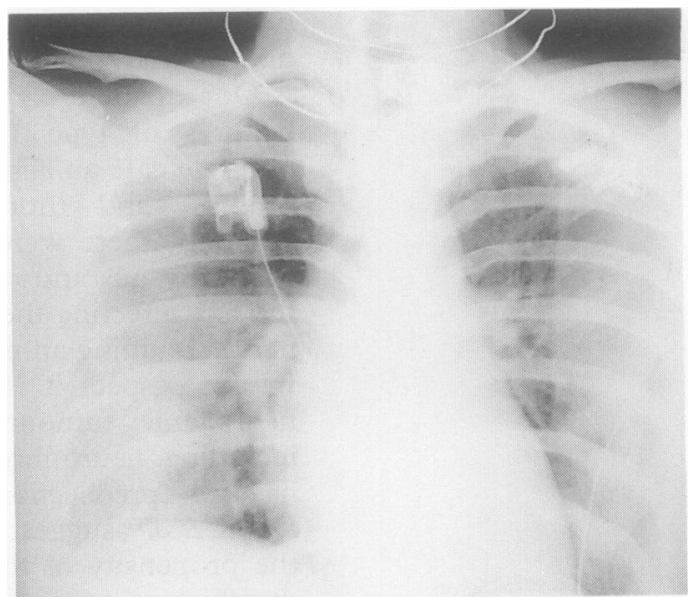

Figure 1 Chest radiograph showing a fine reticular pattern in both lungs after exposure to smoke originating from the defective microwave oven. 
Absolute and relative values from pulmonary function tests performed on the day after admission and 30 and 120 days later compared with normal values

\begin{tabular}{|c|c|c|c|c|c|c|c|}
\hline & \multirow[b]{3}{*}{$\begin{array}{l}\text { Normal } \\
\text { values }\end{array}$} & \multicolumn{6}{|c|}{ Days after event } \\
\hline & & \multicolumn{2}{|l|}{1} & \multicolumn{2}{|l|}{30} & \multicolumn{2}{|l|}{120} \\
\hline & & Absolute & $\begin{array}{l}\text { Relative } \\
(\%)\end{array}$ & Absolute & $\begin{array}{l}\text { Relative } \\
(\%)\end{array}$ & Absolute & $\begin{array}{l}\text { Relative } \\
(\%)\end{array}$ \\
\hline $\operatorname{TLC}(\mathrm{ml})$ & 5190 & 4160 & 80 & 4100 & 79 & 3840 & 73 \\
\hline $\mathrm{VC}(\mathrm{ml})$ & 3840 & 2960 & 77 & 3130 & 81 & 3090 & 80 \\
\hline $\mathrm{FEV}_{1}(\mathrm{ml})$ & 3220 & 2810 & 87 & 2970 & 92 & 2870 & 89 \\
\hline FEV, VC (\%) & 84 & 95 & 113 & 95 & 113 & 93 & 110 \\
\hline \multicolumn{8}{|l|}{ TLCO } \\
\hline $\begin{array}{l}(\mathrm{mmol} / \mathrm{kPa} / \mathrm{min}) \\
\mathrm{TlCO}_{\mathrm{LA}}\end{array}$ & $9 \cdot 5$ & $2 \cdot 1$ & 53 & 5.3 & 36 & $3 \cdot 2$ & כל \\
\hline$(\mathrm{mmol} / \mathrm{kPa} / \mathrm{s} / \mathrm{l})$ & $27 \cdot 5$ & $22 \cdot 5$ & 82 & $22 \cdot 7$ & 82 & $22 \cdot 0$ & 80 \\
\hline
\end{tabular}

TLC - total lung capacity; VC-vital capacity; $\mathrm{FEV}_{1}$-forced expiratory volume in one second; TLCO-carbon monoxide diffusion capacity; TLCO/VA-TLCO corrected for alveolar volume

Figure 2 Histological section of the lung of $a$ parakeet with pronounced hyperaemia and partial atelectasis.

trate on the chest radiograph, and a restrictive ventilatory defect with diminished carbon monoxide transfer. Furthermore, there was a considerable leucocytosis.

All these findings can be explained by the inhalation of a toxic gas that apparently originated from the microwave oven. It seems probable that the patient's lungs suffered a reaction similar to that seen in the parakeets. Morphological aspects of defence mechanisms in the lungs in reaction to inhaled particles and gases have been shown to be similar in laboratory animals and humans. There is, however, a quantitative difference. ${ }^{1}$ Birds are extremely sensitive to inhalation of toxic gases, ${ }^{2}$ traditionally being used by miners to detect mine gases. Recently, during the Gulf war, birds were used to detect poisonous gases after scud attacks.

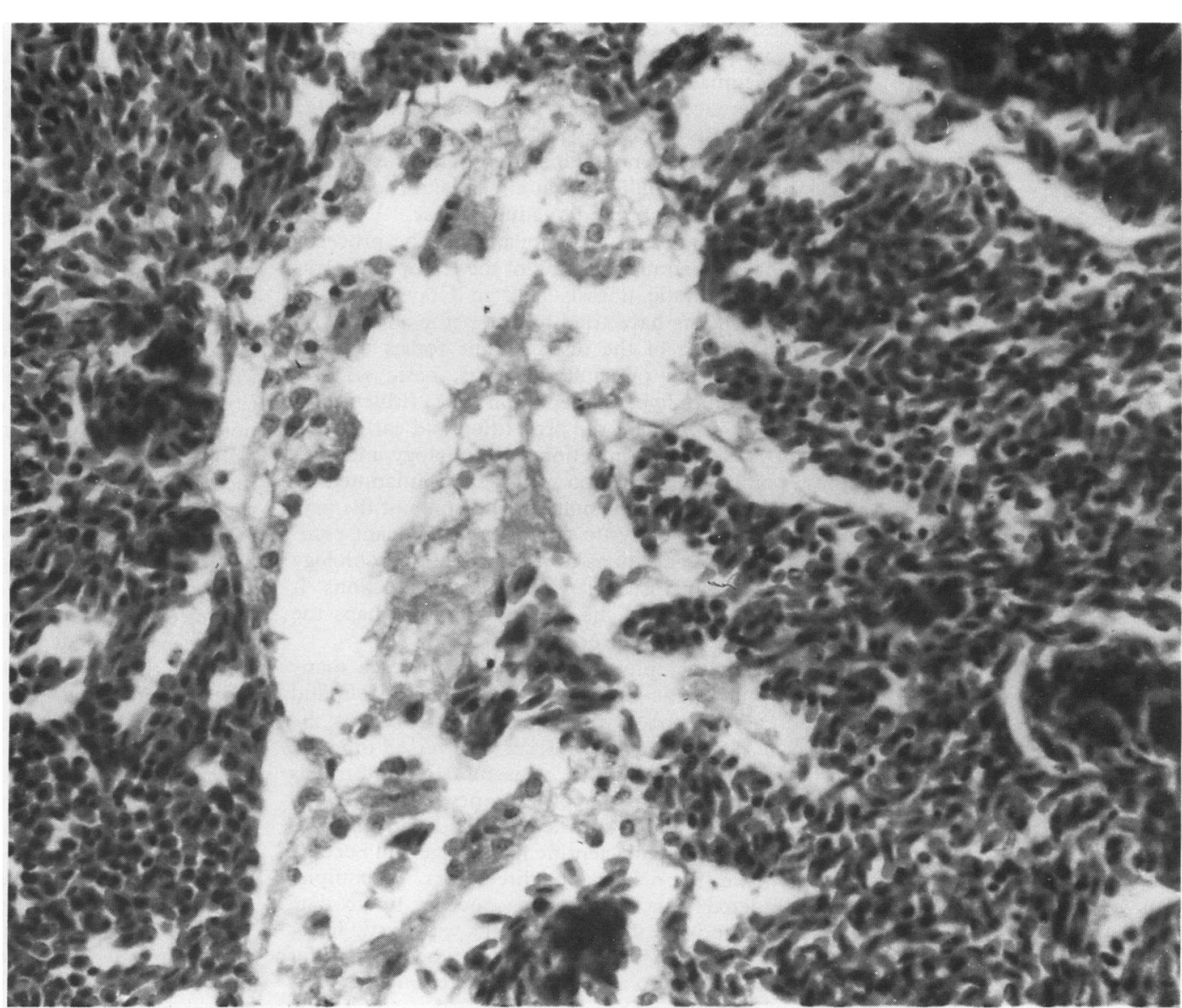

The most probable source for the production of gas is the Teflon (polytetrafluoroethylene, PTFE) block, which was clearly melted and scorched black on top. The glass platform was broken and scorched from underneath, also pointing to the Teflon block as the source of smoke. It seems less probable that the source of the combustion products was the food container since it was not damaged, or the food itself, which consisted of potatoes. After elaborate examination no technical defects to explain the apparent overheating could be found in the microwave oven. Overheating and melting of the Teflon block could not be reproduced by making all kinds of possible human errors in laboratory conditions. Thus the cause of the overheating remains unclear.

Fluoropolymers, especially PTFE, are increasingly used in domestic appliances and are thought to have good fire resistance properties. In non-flaming conditions, however, their thermal degradation products may be 1000 times as toxic as wood and most other materials. The highest toxicity occurs when the primary decomposition products are subjected to continuous secondary heatings. ${ }^{34}$ The human inhalation reaction to PTFE pyrolysis fumes is described as a temporary flu like condition often subsiding spontaneously without treatment (polymer fume fever). ${ }^{5}$ Serious acute pulmonary effects are reported in a number of cases. ${ }^{6-8}$ The reported cases with pulmonary oedema appear to have had heavier exposures. Inhalation of an aerosol of $1 \%$ calcium chloride can be used as a specific antidote. Further treatment consists 
of administration of oxygen and, if needed, corticosteroids. ${ }^{910}$

Reports about health hazards of microwave ovens are few. ${ }^{11}$ PTFE is also used in nonstick plastic coated frying pans, which are reported to give the same toxic symptoms to both humans and birds after overheating. ${ }^{2}$ Birds should preferably not therefore be kept in the kitchen.

1 Wahrheit DB. Interspecies comparisons of lung responses to inhaled particles and gasses. Crit Rev Toxicol 1989 20:1-29.

2 Blandford TB, Seamon PJ, Hughes R, Pattison M, Wilderspin MP. A case of polytetrafluoroethylene poisoning in cockatiels accompanied by polymer fume fever in the owner. Vet Rec 1975;96:175-6.

3 Purser DA. Recent developments in understanding of the toxicity of PTFE thermal decomposition products Presented at the International Conference on Fires in Buildings, September 1989, Toronto, Canada.

4 Williams SJ, Baker BB, Lee KP. Formation of acute pulmonary toxicants following thermal degradation of perfluorinated polymers: evidence for a critical atmospheric reaction. Fd Chem Toxicol 1987;25:177-85.

5 Harris DK. Polymer fume fever. Lancet 1951;ii:1008-11.

6 Robbins JJ, Ware RL. Pulmonary edema from Teflon fumes. N Eng f Med 1964;271:360-1.

7 Evans EA. Pulmonary edema after inhalation of fumes from polytetrafluoroethylene (PTFE). $\mathcal{F}$ Occup Med 1973;15:599-601.

8 Williams N, Atkinson GW, Patchefsky AS. Polymer fume fever: not so benign. F Occup Med 1974;16:519-22.

9 Heierli ChP. Erstbehandlung bei Reizgasinhalation in einem Betrieb. Ther Umsch 1989;46:786-8.

10 Mofenson HC, Caracio TR. Fluorine and fluoride. In: Clinical management of poisoning and drug overdose. 2nd edn. Philadelphia: WB Saunders, 1990.

11 James MI. Burns from fluid heated in a microwave oven. BMF 1989;298:1452.

\section{BOOK NOTICES}

Cystic Fibrosis, Basic and Clinical Research. Edited by Niels Høiby and Svend Stenvang Pedersen. (Pp205; DFl205.00). Amsterdam: Elsevier, 1992. ISBN 0444813780

Cystic fibrosis is one of the fast advancing fields in respiratory medicine. During the next decade $90 \%$ of the children with cystic fibrosis will become adults requiring continuing care into their third and fourth decades. The majority of respiratory physicians will need to become knowledgeable about a disease which is complex, time consuming, and emotionally demanding to treat. Although the mortality of the disease is related to progressive suppurative lung disease, considerable morbidity is also associated with diabetes, hepatobiliary disease, gastrointestinal disease, malnutrition, arthropathy, and vasculitis. The growing interest in this disease is reflected in an annual American conference, a biennial European conference and a triennial world conference. The increase in scientific knowledge of cystic fibrosis is progressing at a breathtaking rate which at present is not matched by any therapeutic breakthrough. It is unlikely that any breakthroughs will alter the established burden of adult disease.

This book represents a compilation of the proceedings of the 17th annual meeting of the European working party for cystic fibrosis held in Copenhagen in 1991. The editors have tried to reflect the clinical and scientific breadth of the disease. The topics covered are screening and prenatal diagnosis; basic science; metabolism and hyperalimentation; the virulence of Pseudomonas aeruginosa; the prevention and early treatment of Pseudomonas infection; immunology and vaccines; lung inflammation and anti-inflammatory treatment; organ transplantation; and some of the psychosocial aspects of cystic fibrosis. A significant component of the proceedings deals with the microbiology and treatment of Pseudomonas aeruginosa infections. It reflects the interest of the editors and is perhaps the main strength of these proceedings.

The respiratory physician who does not see many patients with cystic fibrosis would probably not find this an easy first book with which to get to know the subject in depth, but the clinician well versed in cystic fibrosis care would find it a useful addition to his library. The cost of the book is somewhat high when the advancing state of knowledge is so rapid that it is likely that the current scientific knowledge will become outdated over the next two or three years. To complement updated texts such as this one, an up to date clinical textbook on the care of adults with cystic fibrosis is also needed which will serve as a benchmark for those physicians who expect to see increasing numbers of adults with cystic fibrosis.-AKW

Sulphur Dioxide, Acid Aerosols and Particulates. 2nd Report. Advisory Group on the Medical Aspects of Air Pollution Episodes. (Pp157; £30). London: HMSO, 1992. ISBN 0113215320

This book, the second report produced by the Advisory Group on Medical Aspects of Air Pollution Episodes, was set up to provide advice to the Chief Medical Officer of the potential hazards of sulphur dioxide, acid aerosols, and particulates. The first report dealt with the effects of ozone. The major problem of air pollution by smoke from the burning of coal has largely been overcome in the wake of the Clean Air Acts of 1956 and 1958, but it must be remembered that solid smokeless fuels can contribute local levels of carbon dioxide even if there is no smoke. The group, under the chairmanship of Professor Stephen Holgate, included both clinical and non-clinical scientists. It seems, however, that the epidemiological approach might have been given more emphasis to fit in with the experimental approaches.

Asthma has become more common, and this is a result of air pollution; but is it, and how easy is this to confirm scientifically? Asthma and allergies are certainly more common in children and there are many studies to confirm this. The emphasis in this report is on sulphur dioxide. The available evidence indicates that individuals not suffering from respiratory disease will not be affected by elevated concentrations of sulphur dioxide as occur in the UK. In patients with asthma who are more sensitive to sulphur dioxide the levels in the UK regularly exceed those at which effects of clinical significance occur. When the hourly concentrations of sulphur dioxide are in the range of $125 \mathrm{ppb}$ $\left(357.5 \mu \mathrm{g} / \mathrm{m}^{3}\right)$ to $400 \mathrm{ppb}\left(1144 \mu \mathrm{g} / \mathrm{m}^{3}\right)$ advice on possible clinical effects should be made available. There is no evidence that wearing smog masks is necessary, but asthmatic patients may need to increase their treatment and spend less time out of doors, particularly if the weather is cold. Episodic or long term exposure to particulate matter is low and probably not a health hazard, but epidemiological data linking cancer with exposure to ambient levels of air pollutants other than cigarette smoke are very few. Too few data are available regarding acid aerosol levels to allow any assessment of their effects, although asthmatic patients are more sensitive than normal individuals to levels of acid aerosols as shown by changes in indices of lung function. The report indicates that further research is necessary because of lack of data. Epidemiological research is required on the low levels of air pollutants, the prevalence of respiratory disease, and the incidence of asthma attacks. Little is known about interactions of sulphur dioxide with related pollutants, and with other pollutants such as nitrogen dioxide and ozone.

If you do not have the time to read and study all of this comprehensive report with its multiplicity of figures and tables, spend five minutes reading Chapter 8 Summary, Discussion and Recommendations.-AWF 